\title{
Unraveling the links between rapid automatized naming (RAN), phonological awareness, and reading
}

Article

Accepted Version

Powell, D. ORCID: https://orcid.org/0000-0002-3607-2407 and Atkinson, L. (2021) Unraveling the links between rapid automatized naming (RAN), phonological awareness, and reading. Journal of Educational Psychology, 113 (4). pp. 706718. ISSN 0022-0663 doi: https://doi.org/10.1037/edu0000625 Available at https://centaur.reading.ac.uk/73301/

It is advisable to refer to the publisher's version if you intend to cite from the work. See Guidance on citing.

To link to this article DOI: http://dx.doi.org/10.1037/edu0000625

Publisher: American Psychological Association

All outputs in CentAUR are protected by Intellectual Property Rights law, including copyright law. Copyright and IPR is retained by the creators or other copyright holders. Terms and conditions for use of this material are defined in the End User Agreement.

www.reading.ac.uk/centaur 
Central Archive at the University of Reading

Reading's research outputs online 
Unravelling the links between RAN, phonological awareness and reading

Daisy Powell ${ }^{1,2}$ and Lynette Atkinson ${ }^{2,3}$

1University of Reading, UK

2University of Roehampton, UK

${ }^{3}$ Hamilton Health Sciences, Canada

Address for correspondence: Daisy Powell, Institute of Education, University of Reading, 4 Redlands Road, Reading, RG1 5EX, UK; phone: +44 181379 2797; email: d.a.powell@reading.ac.uk 


\section{Abstract}

It is well established that phonological awareness (PA) and rapid automatized naming (RAN) tasks reliably predict children's developing word reading abilities, across a wide range of languages. However, existing research has not yet demonstrated unequivocally whether RAN and PA are independently and causally linked to reading, nor fully explored the underlying cognitive mechanisms. Most existing research has assessed PA and RAN in children who may already have some reading skill, making direction of influence hard to ascertain. To address this, the current longitudinal research initially assessed RAN and PA in a very young sample of 91 English children (mean age: $3 ; 11 ; S D=3.7$ months), demonstrated to be non-readers. Children were reassessed on RAN, PA, and word-level reading, 18 months (Time 2) and then a further year later (Time 3). To explore underlying mechanisms, separate measures of reading accuracy and fluency were taken, and reading tasks varied according to the extent to which they required alphabetic decoding and lexical, orthographic knowledge. Path analyses revealed that from Time 1 to Time 2 both RAN and PA predicted word reading, indicating temporal precedence, though there was some degree of reciprocity in these relationships. However, by Time 3, while RAN still predicted accuracy and fluency of reading, PA only predicted reading accuracy. Furthermore, findings suggested that while RAN was robustly related to both alphabetic decoding and lexical, orthographic aspects of reading, PA's relationship was restricted to alphabetic decoding accuracy. Theoretical and practical implications are discussed.

Keywords: Rapid automatized naming (RAN); phonological awareness; reading development; preschool children; longitudinal.

\section{Educational Impact and Implications Statement}

This longitudinal study showed that preschool children's phonological awareness (PA: sensitivity to sounds in words) and performance in rapid automatized naming (RAN: fluency 
in naming familiar objects) went on to predict first steps in alphabetic decoding skill. However, only RAN was also linked to lexical (sight vocabulary) development, and to both fluency and accuracy in reading a further year later. Findings have implications for early screening of potential reading difficulties and for the development of effective interventions. 
A large body of research in recent years has established that across different languages, phonological awareness (PA) and rapid automatized naming (RAN) task performance are strong and reliable predictors of word reading development (e.g. Caravolas et al., 2012; Norton \& Wolf, 2012). However, as explored in full below, there are enduring questions about the degree to which both RAN and PA can be seen as independently and causally related to reading. These issues are compounded by the fact that previous studies have typically involved children who already have some reading ability, making it impossible to establish the direction of influence between RAN, PA and reading. The current study sought to provide novel insights into these important questions though a longitudinal study of very young children who, when RAN and PA were first assessed, were demonstrated to be non-readers, and who were then followed through the onset of reading instruction and assessed on two further occasions over the next two and a half years.

RAN tasks, first developed by Denckla and Rudel (e.g. 1974), require children to name sets of familiar stimuli (letters, digits, objects or colours) as quickly as they can. In addition to RAN's wellestablished relationship with reading, RAN deficits have been shown to be reliably associated with specific reading difficulties (e.g. Manis, Doi, \& Bhadha, 2000). Research has also demonstrated that RAN appears to be a universal predictor of word reading ability across languages (Araújo, Reis, Petersson, \& Faísca, 2014). In spite of the well-established link between RAN and reading, there are key remaining questions about the nature of this relationship. RAN is a highly complex task which requires the coordination of a number of cognitive skills, many of which are shared with reading itself. A longstanding issue concerns the degree to which it is the phonological aspect of RAN that accounts for its relationship to reading. Consistent with this account, children's performance on RAN and PA tasks tend to be modestly correlated (Swanson, Trainin, Necoechea, \& Hammill, 2003), and some researchers have argued that phonological processes largely mediate the relationship between RAN and reading accuracy (Bowey, McGuigan, \& Ruschena, 2005; Savage, Pillay, \& Melidona, 2007). On the other hand, many other studies have demonstrated that RAN performance accounts for unique variance in reading accuracy, even after controlling for phonological processing 
(Manis et al., 2000), that RAN performance and PA can dissociate in developing readers (Powell, Stainthorp, Stuart, Garwood, \& Quinlan, 2007), and that some children with dyslexia have RAN difficulties in the absence of phonological processing difficulties (e.g. Wolf \& Bowers, 1999). These findings are in line with the Double Deficit theory of dyslexia (Wolf \& Bowers, 1999), according to which a single RAN deficit can be cause of dyslexia, independent of phonological awareness deficits.

Thus the nagging question of RAN's independence of phonological processing as a predictor of reading remains contentious. As outlined by Araújo et al. (2014), the evidence certainly suggests that the relationship between RAN and reading varies according to a range of factors, including the age and stage of reading development of children involved, the language under investigation, and the nature of both the RAN (alphanumeric versus non-alphanumeric) and the reading (accuracy versus fluency) task used, and these factors may also account for the mixed findings in the literature.

As noted above, RAN tasks require coordinated input from a range of cognitive processes, many of which are also involved in reading itself. Indeed, the surface similarities between RAN and reading raise the possibility that RAN is as much a consequence as a cause of reading ability: it may be that children's experience with print leads to improved performance on RAN tasks, certainly alphanumeric versions of RAN (Bowey, 2005). This raises a fundamental issue of causality, similar to that noted by Castles and Coltheart (2004) in relation to the link between PA and reading. Castles and Coltheart (2004) argued that experimental training studies provide the clearest evidence of causality, pointing out that in spite of the very well-established link between PA and reading, training studies had not yet unequivocally demonstrated the effectiveness of training on phonemic awareness alone (without concurrent training on letter sounds) in promoting word reading ability. With regard to RAN, the few RAN training studies (see Kirby et al., 2010, for a review) that have been carried out to investigate whether a) RAN is amenable to improvement through training and b) whether any gains in RAN are reflected in gains in reading, have similarly failed to provide compelling evidence of a causal link from RAN to reading. 
While longitudinal studies, as they are correlational, cannot provide conclusive evidence of causality, the large number of longitudinal studies showing that RAN predicts reading across the wide range of languages that have been studied (see Georgiou, Parrila, \& Papadopoulos, 2016, for a review) are nevertheless consistent with a causal account. More evidence can be drawn from the small number of cross-lagged, longitudinal studies that have directly investigated the direction of relationships between RAN and reading. However, these have provided inconsistent results with some indicating a unidirectional relationship between RAN and reading (Lervåg \& Hulme, 2009; Wei, Georgiou, \& Deng, 2015) and others a reciprocal one (Compton, 2003; Wolff, 2014). As these studies involve children of a range of different ages, who learn to read in languages varying considerably in orthographic consistency (see below), it is difficult to draw clear conclusions from a comparison between them.

More recently, increased interest in these causal questions has been reflected in two, large scale cross-lagged longitudinal studies (Landerl et al., 2018; Peterson et al., 2018) providing an important contribution to knowledge of the direction of the relationship between RAN, PA and reading, across a range of different languages which differ in orthographic consistency, that is, the extent to which the relationship between letters and sounds are consistent and predictable. English has an inconsistent orthography with many inconsistent words (e.g. "pint", relative to "hint", "mint"). Peterson et al. (2018) revealed that RAN predicted reading efficiency across languages varying in consistency (English, Swedish, Norwegian), but that in the youngest children (at the end of pre-kindergarten), early literacy also predicted RAN, suggesting that RAN skill develops at least in part as the product of learning to read. Landerl et al.'s (2018) cross-linguistic study also investigated cross-lagged paths between RAN, PA and reading, in groups of slightly older children (from Grade 1 to Grade 2) learning to read in English, French, German, Dutch and Greek. In contrast to Peterson et al. (2018), they reported that while RAN consistently emerged as a robust predictor of reading efficiency, reading was not a predictor of RAN in any of the languages studied. It is worth noting that reading ability was not assessed at baseline in either study, and it is therefore possible that at least 
some participants had some reading skill, and thus that the relationship between RAN and early literacy measures may have been mediated by reading itself.

While the studies outlined above clearly demonstrate an association between RAN and reading, as noted above they are correlational in nature and causal inferences are complicated by the fact that children were typically initially assessed when they were already learning to read, albeit often in the early stages. This makes it difficult to demonstrate the temporal precedence of RAN with regard to reading, an important prerequisite to claims that the RAN-reading link is a causal one. A similar issue was raised by Castles and Coltheart (2004) with regard to the relationship between PA and reading. Surprisingly few longitudinal studies have ensured that children were non-readers when first assessed, and those that have used relatively lenient criteria (e.g. Torppa et al., 2013), or assumed children could not read because they had not yet started school, even in countries where schooling starts relatively late (e.g. at age 6 in Norway, in the case of Lervag \& Hulme, 2009), raising questions about the validity of this assumption.

Thus, questions remain about whether RAN, when assessed in children who are nonreaders, predicts and is genuinely antecedent to reading. It is also clear that this issue may vary with a range of other factors, such as the consistency of the orthography, and the nature of the reading task. It has been argued that RAN is more strongly linked to measures of reading efficiency than reading accuracy, and that the less consistent the orthography, the less strong the link between RAN and reading (Araújo et al., 2014). Conversely, PA has been suggested to be less strongly and enduringly related to reading development in more consistent orthographies (De Jong \& Van der Leij, 1999; Furnes \& Samuelsson, 2010). This is perhaps because phonological awareness appears to be more strongly linked to measures of reading accuracy than of reading efficiency (Georgiou, Parrila, Kirby, \& Stephenson, 2008; Poulsen, Juul, \& Elbro, 2015), which tends to quickly asymptote in readers of consistent orthographies. 
Paradoxically, however, in studies involving the English language, it is the reading of precisely those inconsistent words that characterize the language's opaque orthography that has been particularly linked to RAN performance. For example, Clarke, Hulme, and Snowling (2005) found that RAN predicted exception word reading, after phonological skills were accounted for, and other researchers have reported that RAN appears to be particularly linked to tasks requiring orthographic knowledge (Bowers, Sunseth, \& Golden, 1999; Georgiou, Parrila, \& Kirby, 2009; F. Manis, Seidenberg, \& Doi, 1999). However, again, research findings are mixed, with other researchers arguing against a specific link between RAN and orthographic knowledge (Bowey \& Miller, 2007; Moll, Fussenegger, Willburger, \& Landerl, 2009; van den Boer, de Jong, \& Haentjensvan Meeteren, 2013), and others reporting mixed findings, with RAN linked to some but not other orthographic measures (Powell, Stainthorp, \& Stuart, 2014).

These issues raise important theoretical questions. Cognitive models of reading typically postulate (at least) two routes via which a pronunciation can be derived. According to the Triangle model (e.g.Harm \& Seidenberg, 2004; Plaut, McClelland, Seidenberg, \& Patterson, 1996), words are pronounced through activation spreading from orthographic $(\mathrm{O})$ to phonological $(\mathrm{P})$ units, either directly or via a set of semantic (S) units. In this model, consistency as well as word frequency are key determinants of reading efficiency. Because links between $\mathrm{O}$ and $\mathrm{P}$ are less arbitrary than those between either $\mathrm{O}$ or $\mathrm{P}$ and $\mathrm{S}$, direct $\mathrm{O} \rightarrow \mathrm{P}$ mappings are easier to learn than $\mathrm{O} \rightarrow \mathrm{S} \rightarrow \mathrm{P}$ mappings, though this latter route is necessary in particular for reading low frequency words with inconsistent spellings (Harm \& Seidenberg, 2004; Plaut et al., 1996). While this model has not yet been extensively evaluated against developmental data, it is possible that RAN and phonological awareness are differentially linked to the two pathways, with phonological awareness most directly related to the development of the O->P pathway, and RAN skills, which also require efficiency in learning and accessing arbitrary links between objects, colours, digits and letters and their names, may be particularly linked to the O->S->P pathway. 
The requirement of two pathways for reading also defines the Dual Route model of reading (e.g. Coltheart, Rastle, Perry, Langdon, \& Ziegler, 2001). According to this model, words' pronunciations can be derived both through accessing stored, word-specific knowledge via a lexical route, and also through the application of grapheme-phoneme correspondence rules in a non-lexical route. As in the Triangle model, the accuracy and efficiency of the output of the two routes may vary according to the type of letterstring. Words that have not been encountered before (e.g. nonwords) and thus have not been stored in the lexicon can only be read correctly by the non-lexical route, while words with irregular spellings (those that contravene grapheme-phoneme correspondence rules) can only be read correctly by the lexical route, and would generate regularization errors in output from the non-lexical route.

Given its quasi-regular orthography, the English language provides an opportunity to directly test claims that RAN and PA may be involved in distinct cognitive mechanisms underlying reading through assessing whether they are differentially related to the reading of non-words on the one hand and words with inconsistent spellings on the other. However, previous longitudinal studies investigating the predictors of early word reading skill have typically not systematically varied the type of letterstring involved in reading tasks. As a result, the cognitive mechanisms underlying emerging word level reading skills, and how these may change with development, are not fully understood.

The longitudinal paths between RAN and reading have been less extensively researched than those between PA and reading; however, there are also enduring questions about the nature of the link between PA and reading. The research evidence has established that while the role of PA in children's early alphabetic decoding is uncontested, it is necessary but not sufficient for the reading of words with inconsistent spellings, which in addition require word-specific orthographic knowledge. One might predict, therefore, that PA would be a stronger predictor of non-word than inconsistent word reading. Indeed this was what was found by Manis et al. (1999), who also reported that RAN was linked more strongly than PA to tasks such as inconsistent word reading that 
require orthographic knowledge, though as outlined above, research assessing the link between RAN and orthographic knowledge has yielded mixed findings.

The nature of the relationship between PA and reading has been extensively studied, though as noted by Lerner and Lonigan (2016), explicit studies of the developmental origins of PA are relatively scarce. Research has shown that the relationship is complex and bidirectional and varies with children's age, the orthographic consistency of the language (see Melby-Lervåg, Lyster, \& Hulme, 2012, for a review), and importantly with the level of PA assessed. Onset-rime awareness appears to emerge earlier and independent of literacy instruction (Ziegler \& Goswami, 2005), and while phonemic awareness has been shown to be the stronger predictor of reading (Muter, Hulme, Snowling, \& Stevenson, 2004), it has been argued that it may only emerge as a consequence of instruction in an alphabetic writing system (Castles \& Coltheart, 2004).

Thus there are clear remaining questions about the extent to which early reading skill may impact on both RAN and PA, making it difficult to establish the direction of relationships between these constructs in children in the early stages of literacy acquisition, which are important issues in gathering evidence relevant to causality. The principle aim of this study was to shed light on these questions, by examining the longitudinal paths from RAN and PA to reading. The novel contribution made by this study to the literature is in the fact that children's RAN and PA were assessed in very young children who were demonstrated to be non-readers at the first time of testing, to allow us to address enduring questions relating to the causal nature of the relationships between children's performance on these tasks and word level reading. The children's progress was then followed for two and a half years, a period during which literacy instruction commenced. In addition, to try to unravel some of the many remaining questions regarding the links between RAN, PA and reading, separate measures of reading speed and fluency were taken. Finally, the idiosyncratic, inconsistent nature of the English orthography provided the opportunity to address questions regarding the cognitive mechanisms underlying reading: children's performance on reading different types of letterstrings was assessed to allow us to investigate whether RAN performance and PA were 
consistently related to both alphabetic decoding skills (assessed though non-word reading) and lexical, orthographic skills (assessed though word, and specifically exception word reading).

\section{Method}

\section{Participants}

Ninety-eight children (47 girls, 51 boys; mean age = 3 years, 10 months; SD 3.7 months) attending the "Nursery" pre-school year of two state-maintained primary schools in south-east England were initially recruited to the study and completed baseline assessments (Time 1). All children spoke English as their first language. Children attended nursery for three hours per day, either in the morning or the afternoon. Children receive no literacy instruction during the nursery year, though pre-literacy skills (alphabet knowledge, PA) are promoted informally through games and songs. To ensure that children were non-readers at the first time of testing, The British Ability Scales single word reading test (Elliot, Murray, \& Pearson, 1983) was administered. Seven children who could read one or more words were excluded from further analysis, leaving a final sample of 91 children (43 girls; mean age: three years, eleven months; $S D=3.7$ months).

Children were reassessed around 18 months later (Time 2) at the end of their Reception year, the first year of formal literacy instruction in the UK. At this time, 13 of the original sample were no longer available for testing as they had moved school, leaving a sample of 78 children (37 girls; mean age $=5$ years, 3 months; $S D=3.7$ months). This attrition rate (13\%) reflects the fact that there is much movement between schools at this age in the UK. It is also typical of research with similarly aged children (e.g. Hood, Conlon, \& Andrews, 2008; Lonigan, Burgess, \& Anthony, 2000). Children were next assessed around one year later (Time 3 ) during the summer term of Year 1 , at which stage three more children had left the schools, leaving a final sample of 75 children (36 girls; mean age $=6$ years 1 month, $S D=3.4$ months $)$. 


\section{Materials and measures}

To provide measures suitable for use with the very young children in our sample, a combination of standardized and custom-designed tasks was used. Children's performance on each task is summarized in Table 1.

\section{Time 1}

Rapid Automatized Naming (RAN). Object and colour naming tasks were used, which were adapted for use with very young children. Each task involved two trials. On colour naming trials, children were required to name the colours of 16 coloured boxes (four repetitions each of red, yellow, brown and blue in random order). On the two object naming trials, children named 16 objects (four repetitions each of a cow, a fork, an apple and a fish in random order). Children were asked to name colours/objects in the conventional order (left to right, top to bottom) and to assist them a line was drawn through all the objects indicating the order in which they should be named. Scores were calculated by summing the total time taken to name all colours/objects in the two trials. Errors were also recorded, and 5 seconds were added to total RAN scores as a penalty for each error. Data screening revealed significant skew, which was corrected using log transformation. Colour and object naming tasks were significantly correlated $(r=.58, p<.001)$ and a composite RAN measure was created by first standardizing scores on both measures and then taking the mean $z$ score. The composite score was used in subsequent analysis.

As a measure of reliability, the correlation was calculated between scores for the two forms comprising each RAN task (Colours and Objects). The resulting correlations were strong and significant for both subtests (RAN colours: $r=.74$; RAN objects: $r=.84$ ) indicating good reliability.

Phonological awareness (PA). To assess PA, the Rhyme Detection (maximum score $=10$ ) and Word Completion (maximum score $=16$ ) subtests of the Phonological Abilities Test (PAT; Muter, Hulme, \& Snowling, 1997) were used. The rhyme detection task required children to decide which of three words, illustrated with pictures, rhymed with a target (e.g. fish, gun, hat; cat). Cronbach's alpha for this task was reported to be .87 . In the word completion task, children were given the 
beginning of a word and asked to complete it by providing the final syllable in the first eight trials (reported Cronbach's $\alpha=.87$ ) and the final phoneme in the remaining trials (reported Cronbach's $\alpha=$ .93). Pictures accompanied all items. Given a significant correlation between these measures $(r=.29$, $p<.01)$ a composite PA score was calculated, using the same method as above for RAN.

Letter knowledge. The Alphabet Knowledge subtest of the PAT (Muter et al., 1997) was used to assess letter knowledge (maximum score $=26$ ). Test-retest reliability for this task was reported to be .86 . Children were required to give the name or sound for each letter of the alphabet, presented individually in random order. A log transformation was applied to data to correct a significant positive skew prior to analysis.

\section{Time 2:}

Rapid Automatized Naming (RAN). Children completed the RAN colours and objects subtests of the Comprehensive Test of Phonological Processes (CTOPP; Wagner, Torgesen, \& Rashotte, 1999). Both tasks comprised two trials, each requiring children to name six repetitions of six colours/objects. Reported Cronbach's $\alpha$ at age 5 was .87 for RAN objects, and .82 for RAN colours. Total time to name all objects across both trials provided a score for each task. Colour and object naming tasks were significantly correlated $(r=.57, p<.001)$ and a composite score was created, as above.

Phonological awareness (PA). Elision and Sound Matching subtasks of the CTOPP were used. The Elision task required children to omit the first sound (syllable in the first three items, phoneme thereafter) of a word, to produce a new word. There were 20 items, and reported Cronbach's $\alpha$ was .90 at age 5 . In the sound matching task, children had to decide which of three words either started (first 10 items) or ended (remaining items) with the same phoneme as a target word. All words were illustrated with drawings. There were 20 items (reported Cronbach's $\alpha=.93$ at age 5). There was a significant correlation between scores for the two PA tasks $(r=.53, p<.001)$, and a composite was formed, as above. 
Word Reading. Word reading was assessed using the York Assessment of Reading for Comprehension early word reading test (Snowling et al., 2011). The score was the total number of items, of 30, read correctly. Reported Cronbach's $\alpha=.98$.

\section{Time 3:}

Rapid Automatized Naming (RAN). Children again completed the CTOPP colour and object naming tasks (see above). Reported Cronbach's $\alpha$ at age 6 was .80 for colours and .81 for objects. There was a significant correlation between the two RAN tasks $(r=.61, p<.001)$ and a composite score was created, as above.

Phonological Awareness (PA). Children completed the CTOPP elision (see above; reported Cronbach's $\alpha$ at age $6=.92$ ) and blending tasks. In the blending task, each of the 20 items required children to blend a series of sounds to form a word (reported Cronbach's $\alpha$ at age $6=.89$ ). Scores on the two PA tasks were significantly correlated $(r=.46, p<.001)$, and a composite was formed, as above.

Word reading. Word reading accuracy was assessed using the Diagnostic Test of Word Reading Processes (DTWRP; Forum for Research in Language and Literacy, 2012). This test includes 30 regular words, 30 exception words, and 30 non-words, which were presented on separate cards. The number of items read correctly was summed to provide a separate measure for each type of letterstring, with a grand sum computed as a total reading accuracy score. The reliability coefficient for the total reading accuracy score is reported as Cronbach's $\alpha=.99$.

Word reading fluency was assessed using the Test of Word Reading Efficiency (TOWRE; Torgesen, Wagner, \& Rashotte, 1999). This test includes a list of 104 real words and a list of 63 nonwords. The number of words read correctly in 45 seconds provides a measure of word reading fluency, and the number of non-words read correctly in 45 seconds provides a measure of phonemic decoding fluency with summed scores for the two subtests creating an overall reading fluency score. 
The reliability coefficient for the total word reading efficiency score for six year olds is reported as .98.

\section{Procedure}

Time 1: children completed the various measures during the second, spring term of their nursery year. Measures reported here were part of a larger test battery, and were spread across four test sessions each lasting $20-30$ minutes. At Time 2, there was one 20 minute test session. Time 3 data were collected as part of four testing occasions, each lasting $20-30$ minutes. On each testing occasion, children were tested in a quiet area close to their classroom. The order of administration of tasks was counterbalanced within each test session, and where necessary the order in which different sessions were completed was also counterbalanced.

Ethical approval for the study was gained following the University of Roehampton's Ethics procedures and consent was obtained from participants' parents, and from headteachers. Children gave verbal assent to participating at each time point.

\section{Results}

Correlations between variables at Time 1, Time 2 and Time 3 are shown in Table 1, with simple correlations shown above the diagonal. Variables were residualized for age (Durand, Hulme, Larkin, \& Snowling, 2005) and correlations between the resulting age-independent variables shown below the diagonal. The relationships among the age-controlled variables showed a similar pattern to the simple correlations, though the magnitudes of the relationships tended to be slightly lower. Only relationships between age-independent variables are referred to further below.

Table 1 around here 
As shown in Table 1, all correlations between variables were significant, indicating both stability in measurement of the key constructs (reading, RAN and PA) across time, and correlations between these constructs, which are known to be associated in beginning readers (Swanson et al., 2003). The correlation between RAN and PA was moderate at all time points (Time 1: -.38; Time 2: .49; Time 3: -.33), though highest at Time 2, at the end of the children's first year of literacy instruction. The magnitude of these correlations is consistent with that reported elsewhere (Swanson et al., 2003), and results suggest that the relationship between RAN and PA is relatively consistent across the onset of literacy instruction. With regard to RAN, there was a moderately strong correlation between RAN at Time 1 and Time $2(r=.53)$, and between Time 1 and Time $3(r=$ .46) measures, and a high correlation between RAN at Time 2 and Time $3(r=.68)$. This was notable as at Time 1 we used colour and object naming tasks adapted to assist the very young children in completing them, whereas at Times 2 and 3 standardized (CTOPP) measures were used. This provides some validation of the adaptations we made to the RAN task used at Times 1 and also suggests that RAN performance is reasonably stable in early childhood.

With regard to PA, it was necessary to use different tasks at different testing times to ensure that the tasks were appropriate for the children, with earlier measures assessing awareness of larger units (syllables, rimes) and later measures focused more on phoneme level PA. In spite of this, there were moderately strong, significant inter-correlations between PA measures at Times 1 and 2, Times 1 and 3 , and Times 2 and 3 ( $r s=.51, .33, .51$, respectively).

As shown in Table 1, there were moderate to large correlations between letter knowledge at Time 1 and all other measures taken at each time point, including both RAN and PA but also all reading measures. Reading measures showed a very high degree of stability, with strong correlations between Time 2 reading accuracy and both Time 3 reading accuracy $(r=.80)$ and reading fluency $(r=.74)$.

\section{Modelling the longitudinal relationships between RAN, PA and reading.}


To examine the extent to which RAN and PA, when assessed prior to reading acquisition, could be considered temporally antecedent to reading, a series of path analyses were carried out using maximum likelihood estimation techniques. Mplus 7.0 software was used (Muthén \& Muthén, 1998-2012). While prior testing ensured that the children were non-readers at Time 1 , as noted above most children could already accurately identify some letters at this point. Letter knowledge at Time 1 was therefore added as a precursor to reading, in all models. This ensured that we did not over-estimate the role of RAN and PA at Time 1, given their substantial correlations $(-.57, .51$, respectively) with letter knowledge at this time.

Given the relatively small sample and to increase the ratio of participants to parameters, we carried out separate path analyses for RAN and $\mathrm{PA}^{1}$. Because it has been suggested that pre-literate RAN is more strongly linked to reading fluency than reading accuracy, and that PA is conversely related more strongly to reading accuracy than fluency (Georgiou et al., 2008; Poulsen et al., 2015), we carried out separate analyses for reading accuracy and reading fluency.

\section{RAN and reading}

To investigate whether RAN, assessed before children could read, could be seen as temporally antecedent to word reading, two path analyses (graphically represented in Figure 1), were carried out, in which we investigated the longitudinal relationships between RAN and a) reading accuracy and $b$ ) reading fluency.

Figure 1 around here

\footnotetext{
${ }^{1}$ To ensure that carrying out separate analyses for RAN and PA did not qualitatively change the pattern of results through inflating paths to reading by including variance shared by PA and RAN, we also carried out path analyses in which both RAN and PA were included, which did not alter the overall pattern of results. NB. In these path models that included both RAN and PA, paths between RAN and PA were always non-significant.
} 
The results showed a very similar pattern for reading accuracy and reading fluency, which are therefore discussed together. Autoregressive paths, between a construct and itself at a later testing time, were moderate to strong, indicating stability of measurement in spite of the fact that first, slightly different versions of the RAN objects and colours tasks were used at Time 1 than at Times 2 and 3, and second, that letter knowledge was used as a proxy for reading at Time 1 . There was a significant path from Time 1 RAN to Time 2 word reading, indicating that RAN assessed in these very young non-readers was indeed a significant predictor of their later emergent word reading abilities, and this was true both for accuracy and fluency. RAN at Time 2 continued to predict reading at Time 3, again for both accuracy and fluency. Letter knowledge at Time 1 was a significant predictor of Time 2 reading but not of Time 2 RAN, indicating some independence between RAN and letter knowledge in their relationship to reading, in spite of the correlation between them, which lends further weight to the argument of RAN's antecedence to literacy. Time 2 reading was, however, a significant predictor of Time 3 RAN, suggesting a bi-directional relationship between RAN and reading, as reading proficiency develops.

Figure 2 around here

\section{PA and reading}

A secondary aim of the current research was to investigate whether the longitudinal paths between RAN and reading were analogous to those between PA and reading, and whether the relationship between PA and reading was greater for reading accuracy than for reading fluency. Two path analyses were carried out to address these questions and are shown in Figure 2.

The analyses involving PA produced rather different results to those involving RAN. The paths between Time 1 and Time 2 PA and reading measures were similar both for reading accuracy and reading fluency, and indicated a reciprocal relationship between PA and reading, at this earliest stage in literacy acquisition. This suggests that PA is antecedent to reading, but that letter knowledge, here used as a proxy for literacy in these preliterate children, also predicted later PA, suggesting from the beginning of literacy development, PA and literacy are reciprocally related. 
Observation of the paths from Time 2 to Time 3 indicated a divergence between results for reading accuracy and fluency. PA at Time 2 was a significant predictor of reading accuracy, but not fluency, at Time 3. However, reading at Time 2 predicted PA at Time 3, confirming the reciprocal link between PA and reading.

\section{The role of RAN and PA in exception vs. non-word reading accuracy}

The next set of analyses sought to probe further the relationships between RAN, PA and reading, to establish whether these vary with type of letterstring (exception word vs. non-word), reflecting different underlying cognitive mechanisms. Separate path analyses were therefore carried out involving DWTRP exception and non-word subscales.

Figure 3 around here

Figures 3 and 4 show path analyses involving both exception word and non-word reading accuracy subscales from the DTWRP, and RAN and PA, respectively. Of interest are the paths from Time 2 to Time 3, as it was only at Time 3 that we were able to obtain separate measures of exception and non-word reading. These figures show that for both RAN and PA there was a different pattern of relationships for exception words than for non-words. Figure 3 shows that there was a significant path from RAN at Time 2 to exception reading, but not to non-word reading. As shown in in Figure 4, the opposite pattern emerged for PA: there was a significant path from Time 2 PA to non-word reading, but not to exception word reading accuracy.

Figure 4 around here

\section{The role of RAN and PA in word vs. non-word reading fluency}

The final set of analyses were carried out to investigate paths between RAN, PA and reading fluency, to shed light on whether patterns were consistent across both word and non-word fluency, assessed using the TOWRE sight word reading and phonemic decoding subscales, respectively. Analyses are graphically represented in figures 5 and 6 , for models involving RAN and PA, respectively. 
Figure 5 about here

Figure 5 shows that the patterns of relationships between RAN and both word and nonword reading fluency were very similar: there was a reciprocal relationship between RAN and reading at Times 2 and 3, both for words and non-words, with paths from Time 2 RAN to non-word reading fluency almost as strong as to word reading fluency.

Figure 6 about here

Finally, moving to the relationship between PA and word and non-word reading fluency, Figure 6 shows that the paths from PA at Time 2 to both word and non-word reading fluency at Time 3 were not significant, indicating that by this point in development PA did not significantly predict reading fluency, even when the task involved non-word reading.

\section{Discussion}

A key novel component of the current research was that it involved children who at the first time of testing were younger than those typically involved in similar research, in order to ensure that these children were genuine non-readers at baseline. It was therefore encouraging that results demonstrated both stability in measurement of the key constructs (reading, RAN and PA) across time, and correlations between these constructs, which previous research has shown to be associated in beginning readers (Swanson et al., 2003). There was also a modest correlation between RAN and PA at each time point, also consistent with that reported elsewhere (Swanson et al., 2003), and results suggest that the relationship between RAN and PA is relatively consistent before and after the onset of literacy instruction.

The first set of path analyses was carried out to examine the extent to which RAN and PA, when assessed prior to reading acquisition, could be considered antecedent to reading, and whether these relationships were uni- or bi-directional. We carried out separate path analyses for RAN and PA because of the relatively small sample, which was a limitation of the study. Unlike much of the existing research, we considered both reading accuracy and reading fluency in separate analyses to 
address remaining questions in the literature concerning the relative strength of relationships between RAN and PA and these different aspects of word-level reading (Georgiou et al., 2008; Poulsen et al., 2015).

\section{The relationship between RAN and reading accuracy and fluency}

Turning first to the relationship between RAN and reading, results showed a very similar pattern for reading accuracy and reading fluency: RAN consistently predicted reading, but letter knowledge (as a measure of early literacy in these non-readers) at Time 1 did not predict Time 2 RAN, though reading at Time 2 did predict RAN at Time 3 . The first phase of the current study, between Time 1 and Time 2, can be considered as the first phase of literacy learning, as it straddles the onset of literacy learning. According to our findings, this indicates that RAN performance was genuinely antecedent to reading, but that letter knowledge, as a measure of early literacy, was not antecedent to RAN, and thus that at this stage, RAN's relationship to reading is independent and unidirectional. Interestingly, from Time 2 to Time 3, the relationship between RAN and reading did appear to be bidirectional. These findings provide an interesting contrast to Peterson et al. (2017), who found a bidirectional relationship between RAN and reading fluency in all but the oldest children in their sample. The difference in findings may be due to the fact that in the current study children were younger, and known to be non-readers at Time 1. Paths from Time 2 to Time 3 , where children in the current study were comparable in age (and possibly in literacy skills, though mean levels of performance were not reported in Peterson et al.) to those in the Petersen et al. study at Times 1 and 2, also showed a reciprocal relationship between RAN and reading.

Results also suggested that (non-alphanumeric) RAN performance accounted for unique variance in the accuracy as well as the fluency of children's emergent reading. These findings contrast with Compton (2003), who reported a bidirectional relationship between alphanumeric RAN and reading, and no relationship between non-alphanumeric RAN and reading, but his sample were older children who were already reading, which perhaps accounts for the inconsistency with findings reported here. Our findings of a bidirectional relationship between RAN and reading also 
contrast with Lervåg and Hulme (2009) and Landerl et al. (2018). Both studies reported a unidirectional relationship between RAN and text reading fluency, though both also involved older children, who may have been more comparable in age and literacy levels with those at the last time point in Peterson et al.'s (2017) study, where a unidirectional finding between RAN and reading efficiency was also reported. In sum, our findings suggest that RAN is temporally antecedent to reading, but as reading skills develop further, the relationship becomes reciprocal. As discussed previously, RAN is a highly complex task eliciting input from a range of cognitive, perceptual, and motor processes, as is reading itself. As development progresses, differing patterns of relationships with reading likely reflect the shifting, and reciprocal, development of the various components of both tasks. RAN is a task, not a cognitive process, and a key goal of future research will be to identify the cognitive mechanism or mechanisms, underlying the potentially causal link between nonalphanumeric RAN performance in young non-readers and their later word-level reading skill. Longitudinal research will establish whether the cognitive mechanisms underlying reading vary with development. This would not just be theoretically interesting but may also suggest interventions, targeting the key cognitive mechanism underlying the RAN-reading link, for reading difficulties associated with poor RAN performance, which have not shown themselves to be amenable to interventions simply involving training on RAN tasks (Kirby et al., 2010).

\section{The relationships between PA and word reading accuracy and fluency}

A further aim of the current research was to investigate the analogous paths between PA and reading. The analyses involving PA produced rather different results to those involving RAN. From Time 1 to Time 2 the path analyses suggested that PA is antecedent to reading, but that letter knowledge, here used as a measure of early literacy in these non-readers, also predicted later PA, suggesting from the beginning of literacy development, PA and literacy are reciprocally related. Observation of the paths from Time 2 to Time 3 indicated a divergence between reading accuracy and fluency. PA at Time 2 was a significant predictor of reading accuracy at Time 3, but not fluency at Time 3. This is consistent with the view that PA is more strongly related to reading accuracy than 
fluency, and may explain the difference with findings reported by Landerl et al. (2018), who reported no significant path from PA to reading in English, though only assessed reading fluency. However, reading accuracy at Time 2 predicted PA at Time 3, confirming the reciprocal link between PA and reading. These findings underscore the value of examining both reading accuracy and fluency in these young children, to provide insights into underlying mechanisms.

As discussed above, there has been much debate about the level of PA most directly related to reading, and the extent to which PA causes, rather than is caused by reading acquisition (e.g. Castles \& Coltheart, 2004; Muter et al., 1998; Ziegler \& Goswami, 2005). While there is now some consensus that it is phonemic awareness that is most closely related to reading development (e.g. Muter et al., 1998), it is also known that children as young as those in our sample at Time 1 are not yet able to master phoneme-level PA tasks. Thus, at Time 1, PA measures used (rhyme detection and word completion) were necessarily more sensitive to PA at the syllable and rime than phoneme level, with Time 2 and Time 3 measures becoming progressively more heavily weighted towards phoneme awareness. The discrepancy between PA tasks at the different time points may account for the non-significant autoregressive path between PA at Time 2 and 3. Nevertheless, results showed a direct path from PA at Time 1 to word reading 18 months later at Time 2, after a year of literacy instruction, but subsequent to this, findings suggested that children's experience with reading itself contributed to development in PA at the phoneme level.

Our findings are partly consistent with the developmental view of PA put forward by Goswami and colleagues (e.g. Ziegler \& Goswami, 2005), that sensitivity to larger unit (onset-rime) PA is a key predictor of reading. However, the fact that the path from Time 2 PA to Time 3 was not significant, once the effect of reading at Time 2 had been accounted for, argues against the notion of larger unit PA as the developmental precursor of phonemic awareness.

\section{The role of RAN and PA in exception vs. non-word reading}


One of the aims of the research was to investigate whether the developmental paths from RAN performance to reading on the one hand, and from PA to reading on the other, varied according to the type of letterstring involved (inconsistent words vs. non-words), to shed light on whether reading of these different types of letterstrings is underpinned by different underlying cognitive processes. We were particularly interested in whether RAN performance might be most strongly related to word reading, particularly of words with inconsistent spellings, given the debate in the literature, outlined above, about whether RAN might be particularly linked to orthographic knowledge. We were also interested in whether PA, on the other hand, might be particularly important for the establishment of phonological decoding skills, of which the purest measure is nonword reading.

In terms of reading accuracy, results suggested that for both RAN and PA there was a different pattern of relationships for exception words than for non-words. There was a significant path from RAN at Time 2 to exception reading, but not to non-word reading, suggesting that in English, and for these beginning readers, RAN appears to be more important for exception word reading, perhaps due to its association with orthographic knowledge, than for alphabetic decoding, as assessed in non-word reading. For PA, on the other hand, there was a significant path from Time 2 PA to non-word reading, but not to exception word reading accuracy. These findings are also in line with expectations, indicating that pre-literate PA may be particularly important for the establishment of alphabetic decoding skills.

Moving to reading fluency, results suggested that the patterns of relationships between RAN and both word and non-word reading fluency were very similar: there was a reciprocal relationship between RAN and reading fluency at Times 2 and 3, both for words and non-words, with paths from Time 2 RAN to non-word reading fluency almost as strong as to word reading fluency. This pattern is consistent with results reported by Peterson et al. (2018), who also reported a longitudinal effect of early reading fluency on RAN in typically developing children at a similarly early stage in reading development. The discrepancy with contrasting reports (Landerl et al., 2018; Lervåg \& Hulme, 2009) 
of a unidirectional relationship from RAN to reading may reflect that these studies involved older children with more advanced reading skills.

However, analyses investigating the longitudinal pathways between PA and reading fluency revealed that PA at Time 2 predicted neither word nor non-word reading fluency, suggesting a lesser role for PA in reading fluency, even at this early stage in development. Our findings are consistent with reports elsewhere of a lesser role for PA in word reading fluency, in English and other more consistent orthographies (e.g. Landerl et al., 2018). Nevertheless it is worth noting that our results differ from those reported by Peterson et al. (2017), who reported a reciprocal relationship between PA and reading fluency. However, an inspection of the standardized path coefficients reported by Peterson et al. revealed that while significant, the paths were very low $(.06 / .04)$. The corresponding path in the current study was rather larger in magnitude (.16/.17), and the non-significant result may reflect low power due to the relatively small sample size (we return to this issue below).

At any rate, our findings certainly suggested that phonological awareness was less strongly associated with the accuracy than the fluency of alphabetic decoding, as assessed most directly in the non-word reading tasks. The previous studies referred to above did not differentiate between children's reading of different types of letterstring, so the current study brings to the literature an additional level of detail in terms of the cognitive processes underlying children's developing reading skills. This finding has implications for the cognitive theories of reading outlined in the Introduction. Within the framework of the dual route model, it has been argued (Ziegler et al., 2008) that phonological awareness is necessary for the formation of grapheme-phoneme correspondences underlying the non-lexical route. Within the framework of the Triangle model, on the other hand, it has been claimed that phonological awareness is instantiated in the degree to which phonological representations are segmental (Harm \& Seidenberg, 1999). Neither account, however, can offer a natural account of why phonological awareness might predict the accuracy, but not the fluency, of non-word reading, taken as a measure of alphabetic decoding. Thus, further empirical research into this area may help refine such models to more clearly reflect the dynamics of reading development. 


\section{General Summary and Conclusions}

Findings add to understanding of the relationships between RAN, PA and reading. Through assessing both reading accuracy and fluency we have provided novel insights into the nature of the relationships between RAN, PA and word reading over the onset and first years of reading acquisition. Longitudinal models showed that both RAN and PA appear to be temporally antecedent to emergent word reading ability, and that there was some bidirectionality in the relationships between reading and both RAN and PA. These relationships varied according to whether accuracy or fluency was included in analyses, underscoring the value of considering these aspects of reading concurrently, certainly in an opaque orthography like English. We have also been able to offer some account of the complex, mixed results of previous similar studies, in light of the age of children participating in studies, and the nature of tasks used. The study further adds to the literature an exploration of how relationships between RAN, PA and reading also vary, at this crucial developmental stage, according to type of letterstring, shedding light on underlying cognitive mechanisms. As predicted, PA appeared to be robustly related to non-word reading accuracy, though did not emerge as a predictor of either exception word reading accuracy or of either word or non-word reading fluency. These findings support the view that PA is implicated in the setting up of alphabetic decoding mechanisms, but is less important in explaining lexical, orthographic processes that are essential for reading inconsistent words, and with development appear to become the primary mechanism for word reading (Schmalz, Marinus, \& Castles, 2012). However, the fact that PA did not predict non-word reading fluency is hard to account for within existing cognitive models of reading, while it is consistent with the view that PA appears to be more strongly related to reading accuracy than reading fluency. RAN performance, on the other hand, emerged as antecedent to both non-word reading fluency (though not accuracy) and also to both exception word reading accuracy and word reading fluency measures. This suggests that cognitive processes underlying RAN performance are related to both alphabetic decoding and lexical, orthographic processes. 
A limitation of the reported research was the relatively small sample size, particularly at Time 2 and Time 3. Further research with a larger sample would allow for longitudinal modeling of latent constructs and would be essential to expand on and replicate current findings. It is important to acknowledge that data reported here are correlational, and thus findings cannot conclusively establish whether the relationships between RAN, PA and reading are causal. However, findings add to the literature in providing evidence of the temporal precedence of RAN performance, in addition to PA, with regard to word-level reading development. In further demonstrating that RAN and PA appear to be more strongly associated with the emergence of different aspects of reading, findings also shed light on potential underlying cognitive mechanisms, which adds further weight to a potentially causal explanation. To take this further, there is a real need for additional detailed, experimental work, to probe in detail these cognitive mechanisms. Recent work of this nature has already led to gains in understanding of aspect of reading, such as work looking at the nature of automaticity, by Jones, Snowling, and Moll (2016), but there remain many unanswered questions relating to these issues.

In sum, through examining, at Time 1, very young children who were demonstrated to be non-readers, this study provides evidence consistent with a causal account of the link between both RAN and PA and reading. Theoretical implications of these findings are discussed above, but findings are also important for practical reasons. With regard to RAN, findings suggest that RAN can be used reliably as a very early screener of potential reading difficulties. Interventions involving PA (alongside letter-sound knowledge) already have a strong evidence base. However, while interventions involving RAN have not proved fruitful, future research identifying the cognitive mechanism or mechanisms underlying RAN's link to reading have the potential to lead to targeted interventions for children with reading difficulties associated with RAN.

\section{References}


Araújo, S., Reis, A., Petersson, K. M., \& Faísca, L. (2014). Rapid automatized naming and reading performance: A meta-analysis. Journal of Educational Psychology, 107(3), 868-883. https://doi.org/10.1037/edu0000006

Bowers, P. G., Sunseth, K., \& Golden, J. (1999). The Route Between Rapid Naming and Reading Progress. Scientific Studies of Reading, 3(1), 37-53.

Bowey, J. A. (2005). Predicting individual differences in learning to read. In Snowling, M. \& Hulme, C. (Eds.), The science of reading: A handbook (pp. 155-172). Oxford, UK: Blackwell.

Bowey, J. A., McGuigan, M., \& Ruschena, A. (2005). On the association between serial naming speed for letters and digits and word-reading skill: Towards a developmental account. Journal of Research in Reading, 28(4), 400-422. https://doi.org/10.1111/j.1467-9817.2005.00278.x

Bowey, J. A., \& Miller, R. (2007). Correlates of orthographic learning in third-grade children's silent reading. Journal of Research in Reading, 30(2), 115-128. https://doi.org/10.1111/j.14679817.2007.00335.x

Caravolas, M., Lervåg, A., Mousikou, P., Efrim, C., Litavsky, M., Onochie-Quintanilla, E., ... Hulme, C. (2012). Common patterns of prediction of literacy development in different alphabetic orthographies. Psychological Science, 23(6), 678-686. https://doi.org/10.1177/0956797611434536

Castles, A., \& Coltheart, M. (2004). Is there a causal link from phonological awareness to success in learning to read? Cognition, 91(1), 77-111. https://doi.org/10.1016/S0010-0277(03)00164-1

Clarke, P., Hulme, C., \& Snowling, M. (2005). Individual differences in RAN and reading: a response timing analysis. Journal of Research in Reading, 28(2), 73-86. https://doi.org/10.1111/j.14679817.2005.00255.x

Coltheart, M., Rastle, K., Perry, C., Langdon, R., \& Ziegler, J. (2001). DRC: A dual route cascaded model of visual word recogntion and reading aloud. Psychological Review, 108(1), 204-256. Retrieved from http://psycnet.apa.org/journals/rev/108/1/204/

Compton, D. L. (2003). Modeling the relationship between growth in rapid naming speed and growth 
in decoding skill in first-grade children. Journal of Educational Psychology, 95(2), 225-239.

https://doi.org/10.1037/0022-0663.95.2.225

De Jong, P., \& Van der Leij, A. (1999). Specific contributions of phonological abilities to early reading acquisition: results from a Dutch latent variable longitudinal study. Journal of Educational Psychology, 91, 450-476.

Denckla, M. B., \& Rudel, R. (1974). Rapid "automatized” naming of pictured objects, colors, letters and numbers by normal children. Cortex: A Journal Devoted to the Study of the Nervous System and Behavior, 10(2), 186-202.

Durand, M., Hulme, C., Larkin, R., \& Snowling, M. (2005). The cognitive foundations of reading and arithmetic skills in 7- to 10-year-olds. Journal of Experimental Child Psychology, 91(2), 113-136. https://doi.org/10.1016/j.jecp.2005.01.003

Elliot, C. D., Murray, D. J., \& Pearson, L. S. (1983). The British Ability Scales. Windsor, UK: NFERNelson.

Forum for Research in Language and Literacy. (2012). Diagnostic Test of Word Reading Processes. Swindon, UK: GL Assessment.

Furnes, B., \& Samuelsson, S. (2010). Predicting Reading and Spelling Difficulties in Transparent and Opaque Orthographies: A Comparison between Scandinavian and US/Australian Children. Dyslexia, 16, 119-142. https://doi.org/10.1007/BF00419342

Georgiou, G. K., Parrila, R., \& Kirby, J. R. (2009). RAN Components and Reading Development From Grade 3 to Grade 5: What Underlies Their Relationship? Scientific Studies of Reading, 13(6), 508-534. https://doi.org/10.1080/10888430903034796

Georgiou, G. K., Parrila, R., Kirby, J. R., \& Stephenson, K. (2008). Rapid Naming Components and Their Relationship With Phonological Awareness, Orthographic Knowledge, Speed of Processing, and Different Reading Outcomes. Scientific Studies of Reading, 12(4), 325-350. https://doi.org/10.1080/10888430802378518

Georgiou, G. K., Parrila, R., \& Papadopoulos, T. C. (2016). The anatomy of the RAN-reading 
relationship. Reading and Writing, 29(9), 1793-1815. https://doi.org/10.1007/s11145-016$9653-9$

Harm, M W, \& Seidenberg, M. S. (1999). Phonology, reading acquisition, and dyslexia: insights from connectionist models. Psychological Review, 106(3), 491-528. Retrieved from http://www.ncbi.nlm.nih.gov/pubmed/10467896

Harm, Michael W, \& Seidenberg, M. S. (2004). Computing the meanings of words in reading: cooperative division of labor between visual and phonological processes. Psychological Review, 111(3), 662-720. https://doi.org/10.1037/0033-295X.111.3.662

Hood, M., Conlon, E., \& Andrews, G. (2008). Preschool home literacy practices and children's literacy development: A longitudinal analysis. Journal of Educational Psychology, 100(2), 252-271. https://doi.org/10.1037/0022-0663.100.2.252

Jones, M. W., Snowling, M. J., \& Moll, K. (2016). What Automaticity deficit? Activation of lexical information by readers with dyslexia in a Rapid Automatized Naming Stroop-switch task. Journal Of Experimental Psychology. Learning Memory And Cognition, 42(3), 465-474.

Kirby, J. R., Georgiou, G. K., Martinussen, R., Parrila, R., Bowers, P., \& Landerl, K. (2010). Naming Speed and Reading: From Prediction to Instruction. Reading Research Quarterly, 45(3), 341362. https://doi.org/10.1598/RRQ.45.3.4

Landerl, K., Freudenthaler, H. H., Heene, M., de Jong, P. F., Desrochers, A., Manolitsis, G., ... Georgiou, G. K. (2018). Phonological Awareness and Rapid Automatized Naming as Longitudinal Predictors of Reading in Five Alphabetic Orthographies with Varying Degrees of Consistency. Scientific Studies of Reading, 00(00), 1-15. https://doi.org/10.1080/10888438.2018.1510936 Lerner, M. D., \& Lonigan, C. J. (2016). Bidirectional relations between phonological awareness and letter knowledge in preschool revisited: A growth curve analysis of the relation between two code-related skills. Journal of Experimental Child Psychology, 144, 166-183. https://doi.org/10.1016/j.jecp.2015.09.023 Lervåg, A., \& Hulme, C. (2009). Rapid automatized naming (RAN) taps a mechanism that places 
constraints on the development of early reading fluency. Psychological Science, 20(8), 10401048. https://doi.org/10.1111/j.1467-9280.2009.02405.x

Lonigan, C. J., Burgess, S. R., \& Anthony, J. L. (2000). Development of emergent literacy and early reading skills in preschool children: Evidence from a latent-variable longitudinal study. Developmental Psychology, 36(5), 596-613. https://doi.org/10.1037/0012-1649.36.5.596

Manis, F. R., Doi, L. M., \& Bhadha, B. (2000). Naming speed, phonological awareness, and orthographic knowledge in second graders. Journal of Learning Disabilities, 33(4), 325-333, 374. Retrieved from http://www.ncbi.nlm.nih.gov/pubmed/15493095

Manis, F., Seidenberg, M., \& Doi, L. M. (1999). See Dick RAN: Rapid naming and the longitudinal prediction of reading subskills in first and second graders. Scientific Studies of Reading, 3(2), 129-157. Retrieved from http://psycnet.apa.org/psycinfo/1999-13283-003

Melby-Lervåg, M., Lyster, S.-A. H., \& Hulme, C. (2012). Phonological skills and their role in learning to read: A meta-analytic review. Psychological Bulletin, 138(2), 322-352.

https://doi.org/10.1037/a0026744

Moll, K., Fussenegger, B., Willburger, E., \& Landerl, K. (2009). RAN Is Not a Measure of Orthographic Processing. Evidence From the Asymmetric German Orthography. Scientific Studies of Reading, 13(1), 37-41. https://doi.org/10.1080/10888430802631684

Muter, V., Hulme, C., \& Snowling, M. J. (1997). Phonological Abilities Test. York, UK: Harcourt Brace. Muter, V., Hulme, C., Snowling, M. J., \& Stevenson, J. (2004). Phonemes, rimes, vocabulary, and grammatical skills as foundations of early reading development: evidence from a longitudinal study. Developmental Psychology, 40(5), 665-681. https://doi.org/10.1037/00121649.40.5.665

Muter, V., Hulme, C., Snowling, M., \& Taylor, S. (1998). Segmentation, Not Rhyming, Predicts Early Progress in Learning to Read. Journal of Experimental Child Psychology, 71(1), 3-27. https://doi.org/10.1006/jecp.1998.2453

Muthén, L. K., \& Muthén, B. O. (n.d.). MPlus User's Guide (Seventh Ed). Los Angeles, CA: Muthén \& 
Muthén. https://doi.org/10.1111/j.1600-0447.2011.01711.x

Norton, E. S., \& Wolf, M. (2012). Rapid Automatized Naming (RAN) and Reading Fluency:

Implications for Understanding and Treatment of Reading Disabilities. Annu. Rev. Psychol, 63, 427-452. https://doi.org/10.1146/annurev-psych-120710-100431

Peterson, R. L., Arnett, A. B., Pennington, B. F., Byrne, B., Samuelsson, S., \& Olson, R. K. (2018). Literacy acquisition influences children's rapid automatized naming. Developmental Science, 21(3), 1-9. https://doi.org/10.1111/desc.12589

Plaut, D. C., McClelland, J. L., Seidenberg, M. S., \& Patterson, K. (1996). Understanding normal and impaired word reading: computational principles in quasi-regular domains. Psychological Review, 103(1), 56-115. Retrieved from http://www.ncbi.nlm.nih.gov/pubmed/8650300 Poulsen, M., Juul, H., \& Elbro, C. (2015). Multiple mediation analysis of the relationship between rapid naming and reading. Journal of Research in Reading, 38(2), 124-140. https://doi.org/10.1111/j.1467-9817.2012.01547.x

Powell, D., Stainthorp, R., \& Stuart, M. (2014). Deficits in Orthographic Knowledge in Children Poor at Rapid Automatized Naming (RAN) Tasks? Scientific Studies of Reading, 18(2014), 1-16. https://doi.org/10.1080/10888438.2013.862249

Powell, D., Stainthorp, R., Stuart, M., Garwood, H., \& Quinlan, P. (2007). An experimental comparison between rival theories of rapid automatized naming performance and its relationship to reading. Journal of Experimental Child Psychology, 98(1), 46-68. https://doi.org/10.1016/j.jecp.2007.04.003

Savage, R., Pillay, V., \& Melidona, S. (2007). Deconstructing rapid automatized naming: Component processes and the prediction of reading difficulties. Learning and Individual Differences, 17(2), 129-146. https://doi.org/10.1016/j.lindif.2007.04.001

Schmalz, X., Marinus, E., \& Castles, A. (2012). Phonological decoding or direct access? Regularity effects in lexical decisions of Grade 3 and 4 children. The Quarterly Journal of Experimental Psychology, (2015), 1-9. https://doi.org/10.1080/17470218.2012.711843 
Snowling, M. J, Stothard, S. E., Clarke, P., Bowyer-Crane, C., Harrington, A., Truelove, E., ... Hulme, C. (2011). York assessment of reading for comprehension: Early reading and passage reading Primary (2nd ed.). London, UK: GL Assessment. Retrieved from http://www.glassessment.co.uk/products/york-assessment-reading-comprehension-early-reading-andpassage-reading-primary

Swanson, H. L., Trainin, G., Necoechea, D. M., \& Hammill, D. D. (2003). Rapid Naming, Phonological Awareness, and Reading: A Meta-Analysis of the Correlation Evidence. Review of Educational Research, 73(4), 407-440. https://doi.org/10.3102/00346543073004407

Torgesen, J. K., Wagner, R. K., \& Rashotte, C. (1999). The Test of Word Reading Efficiency. Austin, TX: ProEd.

Torppa, M., Parrila, R., Niemi, P., Lerkkanen, M. K., Poikkeus, A. M., \& Nurmi, J. E. (2013). The double deficit hypothesis in the transparent Finnish orthography: A longitudinal study from kindergarten to Grade 2. Reading and Writing, 26(8), 1353-1380.

https://doi.org/10.1007/s11145-012-9423-2

van den Boer, M., de Jong, P. F., \& Haentjens-van Meeteren, M. M. (2013). Modeling the Length Effect: Specifying the Relation With Visual and Phonological Correlates of Reading. Scientific Studies of Reading, 17(4), 243-256. https://doi.org/10.1080/10888438.2012.683222

Wagner, R. K., Torgesen, J. K., \& Rashotte, C. (1999). Comprehensive Test of Phonological Processes: Administration Manual. Austin, TX: ProEd.

Wei, W., Georgiou, G. K., \& Deng, C. (2015). Examining the Cross-Lagged Relationships Between RAN and Word Reading in Chinese. Scientific Studies of Reading, 19(6), 446-455. https://doi.org/10.1080/10888438.2015.1077447

Wolf, M., \& Bowers, P. G. (1999). The double-deficit hypothesis for the developmental dyslexias. Journal of Educational Psychology, 91(3), 415-438. Retrieved from http://psycnet.apa.org/journals/edu/91/3/415/

Wolff, U. (2014). RAN as a predictor of reading skills, and vice versa: Results from a randomised 
reading intervention. Annals of Dyslexia, 64(2), 151-165. https://doi.org/10.1007/s11881-0140091-6

Ziegler, J. C., Castel, C., Pech-Georgel, C., George, F., Alario, F. X., \& Perry, C. (2008). Developmental dyslexia and the dual route model of reading: Simulating individual differences and subtypes. Cognition, 107(1), 151-178. https://doi.org/10.1016/j.cognition.2007.09.004

Ziegler, J. C., \& Goswami, U. (2005). Reading acquisition, developmental dyslexia, and skilled reading across languages: a psycholinguistic grain size theory. Psychological Bulletin, 131(1), 3-29. https://doi.org/10.1037/0033-2909.131.1.3 
Table 1: Correlations between time 1, 2 and 3 variables, with zero order correlations above the diagonal, and correlations between age-controlled variables below the diagonal. Descriptive statistics (raw scores) are also shown.

\begin{tabular}{|c|c|c|c|c|c|c|c|c|c|c|c|c|c|c|}
\hline & 1. & 2. & 3. & 4. & 5. & 6. & 7. & 8. & 9. & 10. & 11. & 12. & 13. & 14. \\
\hline 1. RAN T1 & - & $-.47^{* * *}$ & $-.58 * * *$ & $.57^{* * *}$ & $-.54^{* * *}$ & $-.47^{* * *}$ & $.58^{* * *}$ & $-0.24 *$ & $-.52^{* * *}$ & $-.40 * * *$ & $-.57 * * *$ & $-.54^{* * *}$ & $-.51 * * *$ & $-.54 * * *$ \\
\hline 2. PA T1 & $-.41 * * *$ & - & $.53 * * *$ & $-.37 * *$ & $.57^{* * *}$ & $.48^{* * *}$ & $-.29^{* *}$ & $.31^{* *}$ & $.44^{* * *}$ & $.45^{* * *}$ & $.39 * * *$ & $.34^{* *}$ & $.36^{* *}$ & $.31 * *$ \\
\hline $\begin{array}{l}\text { 3. Letter } \\
\text { T1 }\end{array}$ & $-.57^{* * *}$ & $.51^{* * *}$ & - & $-.42 * * *$ & $.63 * * *$ & $.58 * *$ & $-.35 * *$ & $.31 * *$ & $.53 * * *$ & $.47 * * *$ & $.55 * * *$ & $.48 * * *$ & $.45^{* * *}$ & $.49 * * *$ \\
\hline 4. RAN T2 & $.58 * * *$ & $-.35 * *$ & $-.41 * * *$ & - & $-.49^{* * *}$ & $-.43^{* * *}$ & $.73^{* * *}$ & $-.27^{*}$ & $-.56^{* * *}$ & $-.46 * * *$ & $-.59 * * *$ & $-.64^{* * *}$ & $-.61 * * *$ & $-.64 * * *$ \\
\hline 5. PA T2 & $-.50 * * *$ & $.53 * * *$ & $.63 * * *$ & $-.48 * * *$ & - & $.72^{* * *}$ & $-.49^{* * *}$ & $.50^{* * *}$ & $.69^{* * *}$ & $.66^{* * *}$ & $.63 * * *$ & $.62^{* * *}$ & $.61^{* * *}$ & $.61 * * *$ \\
\hline $\begin{array}{l}\text { 6. Read acc } \\
\text { T2 }\end{array}$ & $-.55 * * *$ & $.49 * * *$ & $.60 * * *$ & $-.47 * * *$ & $.72 * * *$ & - & $-.48^{* * *}$ & $.64^{* * *}$ & $.81^{* * *}$ & $.70 * * *$ & $.79 * * *$ & $.74^{* * *}$ & $.71^{* * *}$ & $.74 * * *$ \\
\hline 7. RAN T3 & $.55 * * *$ & $-.24 *$ & $-.34 * *$ & $.72 * * *$ & $-.46 * * *$ & $-.49 * * *$ & - & $-.31^{* *}$ & $-.51^{* * *}$ & $-.45^{* * *}$ & $-.52 * * *$ & $-.56^{* * *}$ & $-.56 * * *$ & $-.54 * * *$ \\
\hline 8. РA T3 & $-.24 *$ & $.31 * *$ & $.30 * *$ & $-.27^{*}$ & $.51 * * *$ & $.62 * * *$ & $-.31 * *$ & - & $.70^{* * *}$ & $.69 * * *$ & $.62 * * *$ & $.54^{* * *}$ & $.49 * * *$ & $.55^{* * *}$ \\
\hline $\begin{array}{l}\text { 9. Read acc } \\
\text { T3 }\end{array}$ & $-.52 * * *$ & $.42 * * *$ & $.52 * * *$ & $-.55^{* * *}$ & $.68 * * *$ & $.80 * * *$ & $-.51 * * *$ & $.70 * * *$ & - & $.93 * * *$ & $.94 * * *$ & $.92^{* * *}$ & $.88^{* * *}$ & $.91 * * *$ \\
\hline $\begin{array}{l}\text { 10. Read } \\
\text { acc nw T3 }\end{array}$ & $-.38 * *$ & $.42 * * *$ & $.44 * * *$ & $-.45^{* * *}$ & $.65^{* * *}$ & $.67 * * *$ & $-.44 * * *$ & $.69 * * *$ & $.93 * * *$ & - & $.80 * * *$ & $.81^{* * *}$ & $.81^{* * *}$ & $.79 * * *$ \\
\hline $\begin{array}{l}\text { 11. Read } \\
\text { acc ex T3 }\end{array}$ & $-.58 * * *$ & $.37^{* *}$ & $.54 * * *$ & $-.58 * * *$ & $.62^{* * *}$ & $.82^{* * *}$ & $-.52 * * *$ & $.61^{* * *}$ & $.94 * * *$ & $.80 * * *$ & - & $.93 * * *$ & $.90 * * *$ & $.92 * * *$ \\
\hline $\begin{array}{l}\text { 12. Read } \\
\text { flu T3 }\end{array}$ & $-.53 * * *$ & $.31 * *$ & $.47 * * *$ & $-.63 * * *$ & $.61 * * *$ & $.74^{* * *}$ & $-.55^{* * *}$ & $.54 * * *$ & $.91 * * *$ & $.79 * * *$ & $.92 * * *$ & - & $.98 * * *$ & $.99 * * *$ \\
\hline $\begin{array}{l}\text { 13. Read } \\
\text { flu nw T3 }\end{array}$ & $-.49 * * *$ & $.33 * *$ & $.43 * * *$ & $-.60 * * *$ & $.59 * * *$ & $.71^{* * *}$ & $-.56 * * *$ & $.49 * * *$ & $.88 * * *$ & $.80 * * *$ & $.89 * * *$ & $.97 * * *$ & - & $.93 * * *$ \\
\hline $\begin{array}{l}\text { 14. Read } \\
\text { flu wd T3 }\end{array}$ & $-.54 * * *$ & $.29 *$ & $.48 * * *$ & $-.64 * * *$ & $.60 * * *$ & $.73 * * *$ & $-.54 * * *$ & $.55^{* * *}$ & $.90 * * *$ & $.78 * * *$ & $.91 * * *$ & $.97 * * *$ & $.93 * * *$ & - \\
\hline Mean & 61.29 & 10.65 & 6.80 & 108.96 & 14.89 & 12.92 & 84.84 & 21.71 & 39.58 & 12.80 & 10.95 & 64.61 & 41.08 & 23.53 \\
\hline$S D$ & 20.11 & 5.40 & 7.10 & 28.81 & 6.10 & 7.26 & 22.33 & 6.83 & 19.22 & 6.64 & 6.57 & 29.48 & 17.83 & 12.14 \\
\hline
\end{tabular}

Note: ${ }^{*} p<.05 ; * *<<.01 ; * * *<.001$. RAN = rapid automatized naming; PA = phonological awareness; T1/2/3 = Time $1 / 2 / 3 ;$ Letter = letter knowledge; read acc = reading accuracy; read flu = reading fluency; $n w=$ non-word; ex = exception word; wd = word. 
Figures:

Figure 1: Longitudinal path analysis, with standardized estimates, for RAN and reading at Times 1, 2 and 3. The top panel shows reading accuracy at Time 3, while the bottom panel shows reading fluency at Time 3. Solid lines represent significant relationships; dashed lines represent nonsignificant relationships; dotted arrows show residual variances.

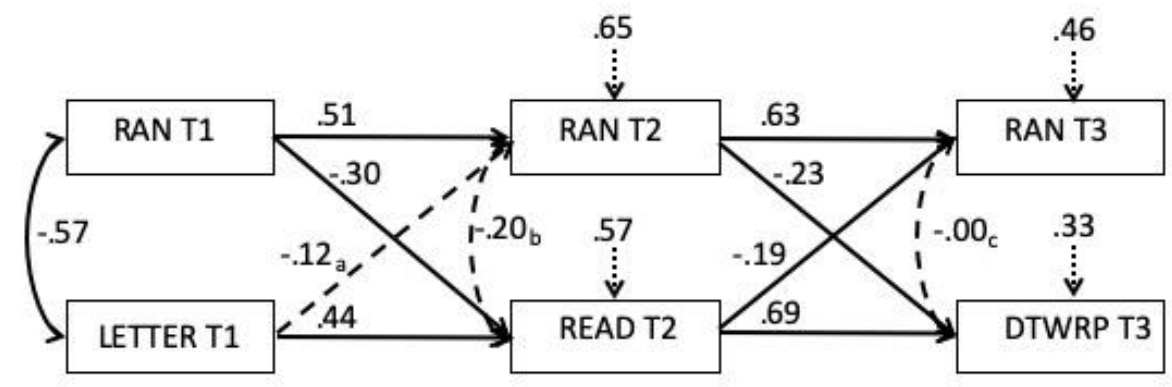

$\chi 2(4)=2.92, n s ; \mathrm{CFI}=1.00 ; \mathrm{RMSEA}=0.00(\mathrm{Cl} .90=0.00$ to .14$)$

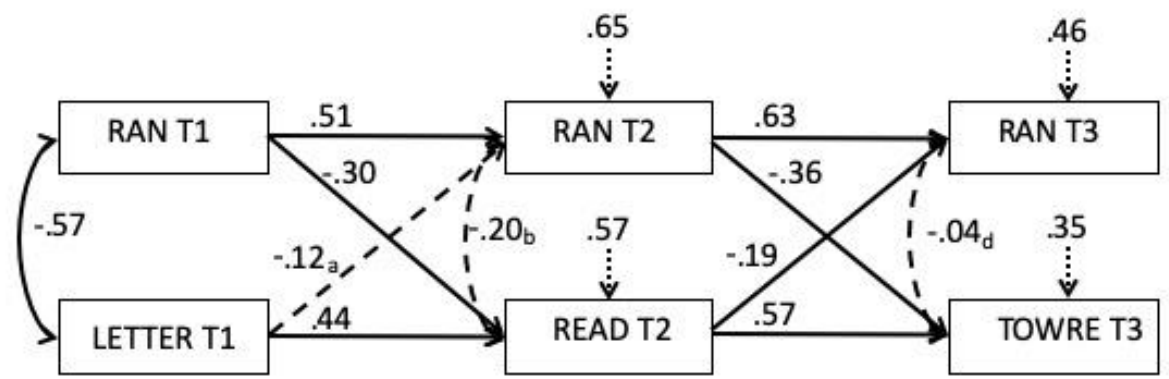

$\chi 2(4)=2.74, n s ; \mathrm{CFI}=1.00 ; \mathrm{RMSEA}=0.00\left(\mathrm{Cl}_{.90}=0.00\right.$ to .13$)$

Note: a: $p=.29 ;$ b: $p=.07 ;$ c: $p=.99 ;$ d: $p=.76$; Letter T1 = letter knowledge at Time 1 ; Read T2 $=$ YARC early word reading (accuracy) test; DTWRP $=$ Diagnostic Test of Word Reading Processes (reading accuracy); TOWRE $=$ Test of Word Reading Efficiency (reading fluency). CFI = Comparative fit index; RMSEA = root mean square error of approximation; $\mathrm{CE}_{.90}=90 \%$ confidence intervals. 
Figure 2: Longitudinal path analysis, with standardized estimates, for RAN and reading at Times 1, 2 and 3. The top panel shows reading accuracy at Time 3, while the bottom panel shows reading fluency at Time 3. Solid lines represent significant relationships; dashed lines represent nonsignificant relationships; dotted arrows show residual variances.

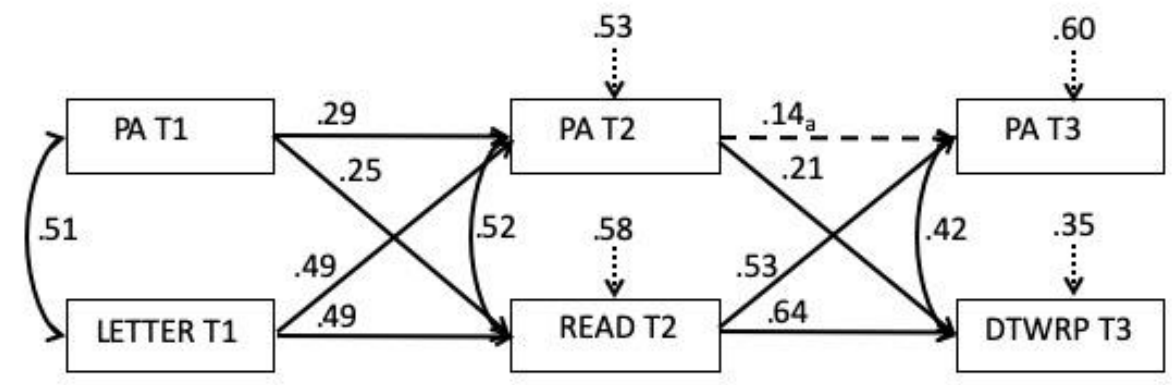

$\chi 2(4)=2.59, n s ; \mathrm{CFI}=1.00 ; \mathrm{RMSEA}=0.00(\mathrm{Cl} .90=0.00$ to .13$)$

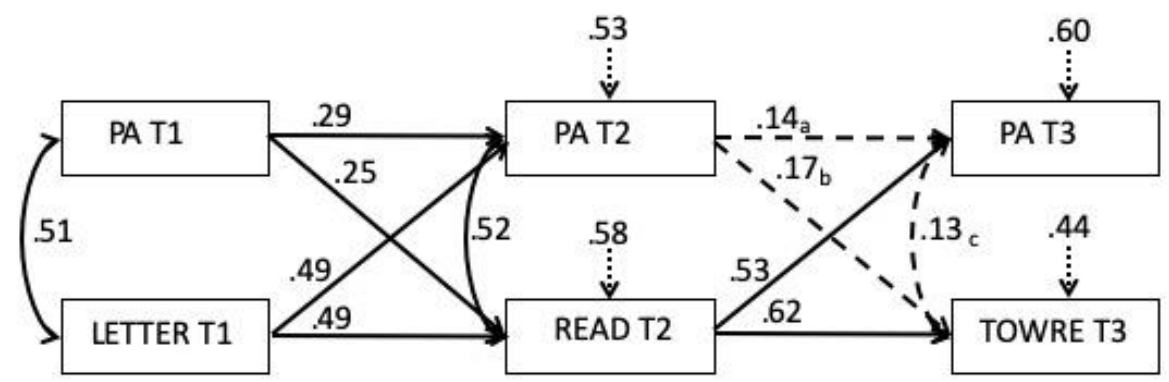

$\chi 2(4)=3.85, n s ; \mathrm{CFI}=1.00 ; \mathrm{RMSEA}=0.00\left(\mathrm{Cl}_{.90}=0.00\right.$ to .16$)$

Note: $: p=.30 ; \mathrm{b}: p=.13 ; \mathrm{c}: p=.26$; Letter T1 = letter knowledge at Time $1 ;$ Read T2 $=$ YARC early word reading (accuracy) test; DTWRP = Diagnostic Test of Word Reading Processes; TOWRE = Test of Word Reading Efficiency. CFI = Comparative fit index; RMSEA = root mean square error of approximation; $\mathrm{CE}_{.90}=90 \%$ confidence intervals . 
Figure 3: Longitudinal path analysis, with standardized estimates, for RAN and reading accuracy (DTWRP) at Times 1, 2 and 3. The top panel shows exception word reading accuracy at Time 3, while the bottom panel shows non-word reading at Time 3. Solid lines represent significant relationships; dashed lines represent non-significant relationships; dotted arrows show residual variances.

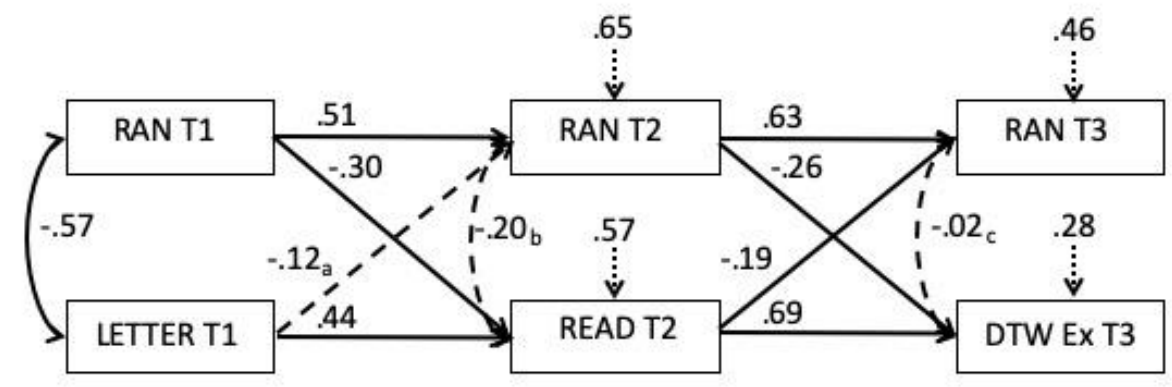

$\chi 2(4)=2.68, n s ; \mathrm{CFI}=1.00 ; \mathrm{RMSEA}=0.00(\mathrm{Cl} .90=0.00$ to .13$)$

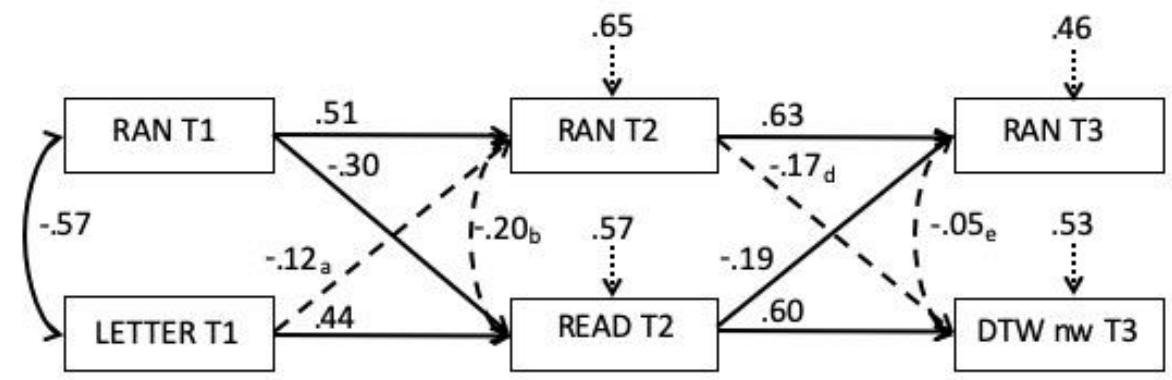

$\chi 2(4)=5.17, n s ; \mathrm{CFI}=0.99 ; \mathrm{RMSEA}=0.057\left(\mathrm{Cl}_{.90}=0.00\right.$ to .18$)$

Note: a: $p=.29 ;$ b: $p=.069 ;$ c: $p=.86$; $p=.075 ;$ е: $p=.71$; Letter T1 = letter knowledge at Time 1; Read T2 = YARC early word reading (accuracy) test; DTW ex = Diagnostic Test of Word Reading Processes exception word reading; DTW nw = Diagnostic Test of Word Reading Processes non-word reading; $\mathrm{CFI}=$ Comparative fit index; RMSEA = root mean square error of approximation; $\mathrm{CE}_{.90}=90 \%$ confidence intervals. 
Figure 4: Longitudinal path analysis, with standardized estimates, for PA and reading accuracy (DTWRP) at Times 1, 2 and 3. The top panel shows exception word reading accuracy at Time 3, while the bottom panel shows non-word reading at Time 3. Solid lines represent significant relationships; dashed lines represent non-significant relationships; dotted arrows show residual variances.

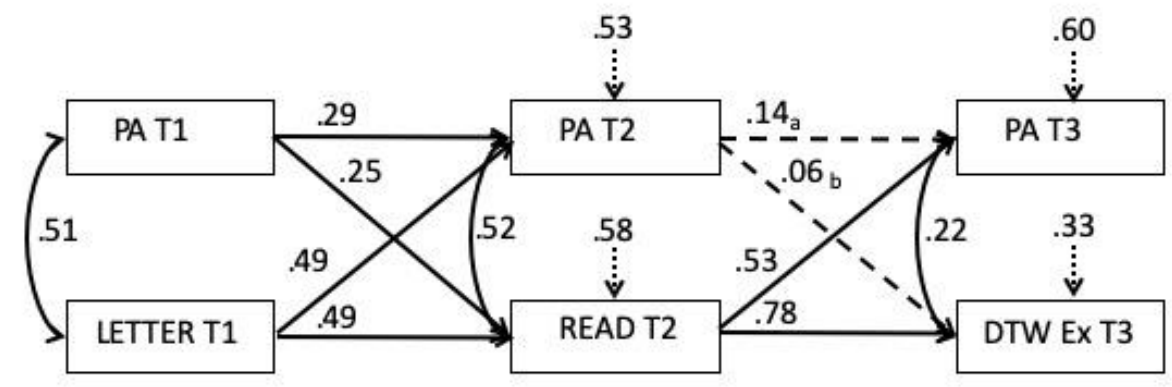

$\chi 2(4)=4.41, n s ; \mathrm{CFI}=0.99 ; \mathrm{RMSEA}=0.03(\mathrm{Cl} .90=0.00$ to .17$)$

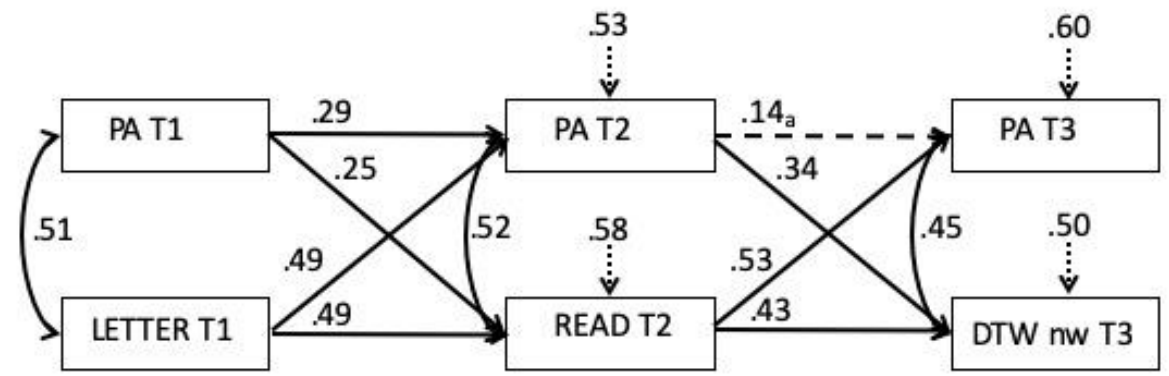

$\chi 2(4)=2.45, n s ; \mathrm{CFI}=1.00 ; \mathrm{RMSEA}=0.00(\mathrm{Cl} .90=0.00$ to .13$)$

Note: $\mathrm{a}: p=.30 ; \mathrm{b}: p=.57$; Letter T1 = letter knowledge at Time 1 ; Read T2 $=$ YARC early word reading (accuracy) test; DTW ex $=$ Diagnostic Test of Word Reading Processes exception word reading; DTW nw = Diagnostic Test of Word Reading Processes non-word reading; $\mathrm{CFI}=$ Comparative fit index; RMSEA = root mean square error of approximation; $\mathrm{CE}_{.90}=90 \%$ confidence intervals. 
Figure 5: Longitudinal path analysis, with standardized estimates, for RAN and reading fluency (TOWRE) at Times 1, 2 and 3. The top panel includes word reading fluency at Time 3, while the bottom panel includes non-word reading fluency at Time 3. Solid lines represent significant relationships; dashed lines represent non-significant relationships; dotted arrows show residual variances.

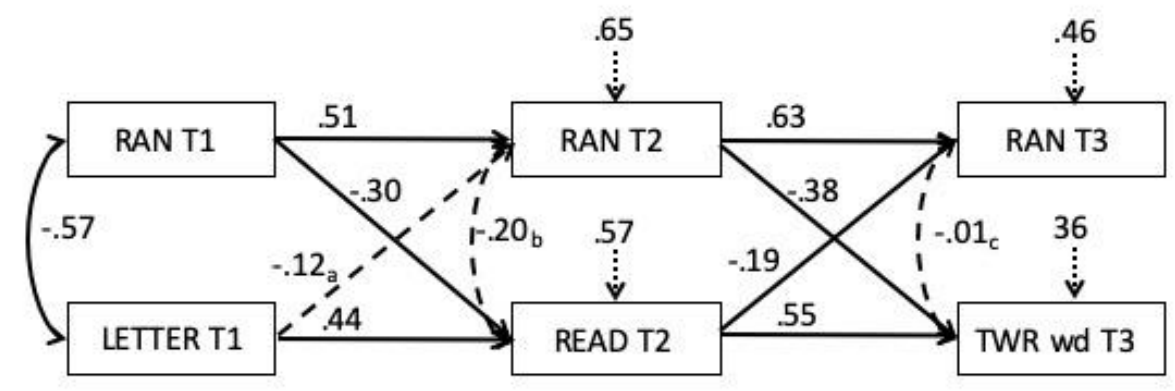

$\chi 2(4)=2.58, n s ; \mathrm{CFI}=1.00 ; \mathrm{RMSEA}=0.00(\mathrm{Cl} .90=0.00$ to .13$)$

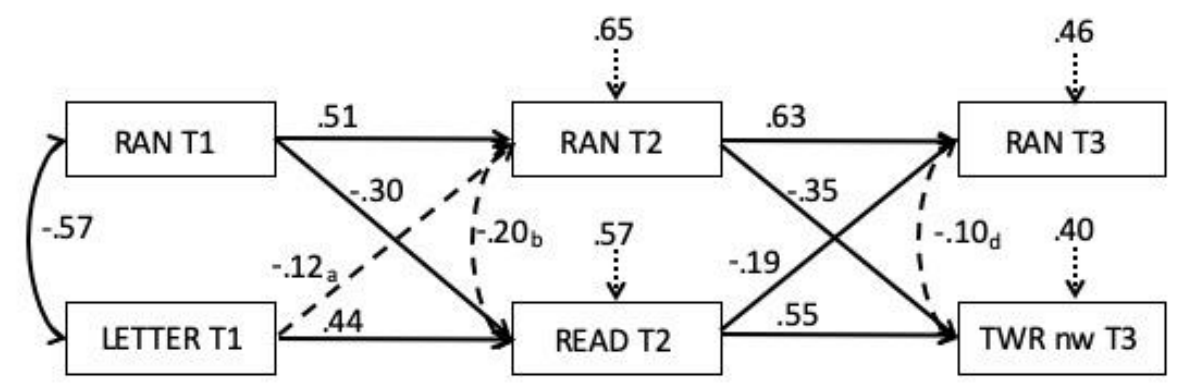

$\chi 2(4)=3.41, n s ; \mathrm{CFI}=1.00 ; \mathrm{RMSEA}=0.000\left(\mathrm{Cl}_{.90}=0.00\right.$ to .15$)$

NB: a: $p=.29 ;$ b: $p=.069 ;$ c: $p=.95 ; \mathrm{d}: p=.40 ;$ Read T2 = YARC early word reading test; TWR $w d=$ Test of Word Reading Efficiency word reading score; TWR nw = Test of Word Reading Efficiency non-word reading score. $\mathrm{CFI}=$ Comparative fit index; RMSEA = root mean square error of approximation; $\mathrm{CE}_{.90}=90 \%$ confidence intervals. 
Figure 6: Longitudinal path analysis, with standardized estimates, for PA and reading fluency (TOWRE) at Times 1, 2 and 3. The top panel shows word reading fluency at Time 3, while the bottom panel shows non-word reading fluency at Time 3. Solid lines represent significant relationships; dashed lines represent non-significant relationships; dotted arrows show residual variances.

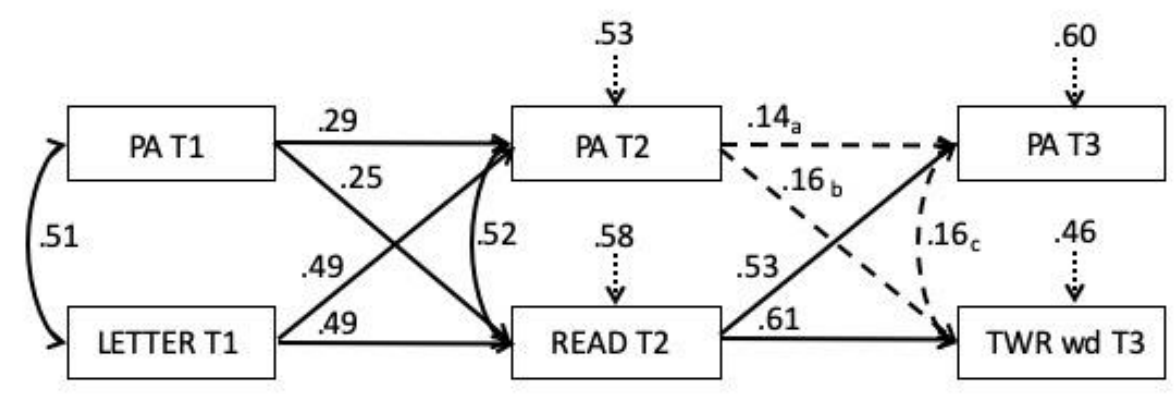

$\chi 2(4)=4.88, n s ; \mathrm{CFI}=0.99 ; \mathrm{RMSEA}=0.05\left(\mathrm{Cl}_{.90}=0.00\right.$ to .17$)$

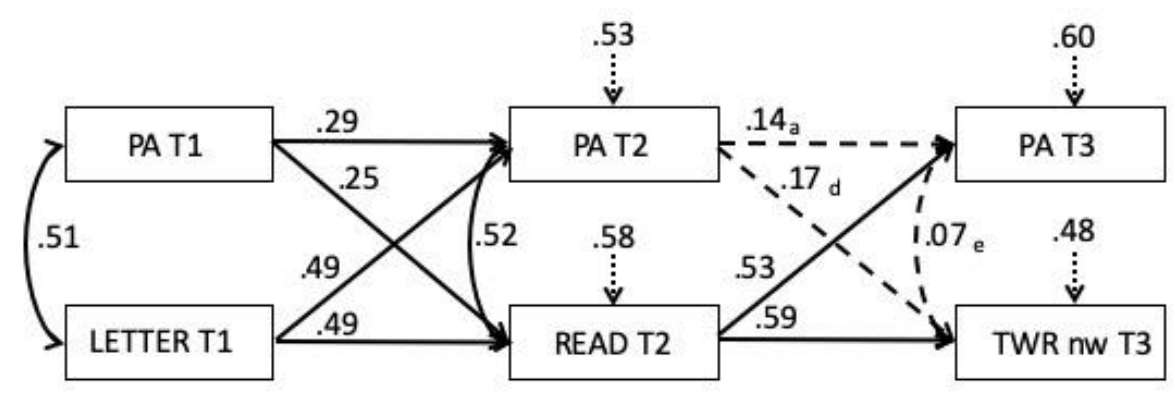

$\chi 2(4)=2.73, n s ; \mathrm{CFI}=1.00 ; \mathrm{RMSEA}=0.00\left(\mathrm{Cl}_{.90}=0.00\right.$ to .13$)$

NB: a: $p=.30 ; \mathrm{b}: p=.15 ; \mathrm{c}: p=.15 ; \mathrm{d}: p=.14 ; \mathrm{e}: p=.53$; Read T2 = YARC early word reading test; TWR wd = Test of Word Reading Efficiency word reading score; TWR nw = Test of Word Reading Efficiency non-word reading score. $\mathrm{CFI}=$ Comparative fit index; RMSEA = root mean square error of approximation; $\mathrm{CE}_{.90}=90 \%$ confidence intervals. 